ARTICLE

\title{
A method of building simulation model for organizational decision-making and inter-organizational control
}

\author{
Shungo Sakaki ${ }^{1}$ \\ Published online: 18 August 2018 \\ (c) The Author(s) 2018
}

\begin{abstract}
This paper presented a method on the configuration of a social simulation model intended for general-purpose application as "inter-system control model", for analyzing real societies engaged in complex and diverse organizational decision-making. The model in this paper is a micro-agent-based model, configured using one replicator dynamics for each decision-making behavior, whether the agent is an organization or an individual. Through the model in this paper, it is possible to configure broad types of decision-making model by individuals, internal organization of corporations, inter-corporate relations and the national economy. This paper describes a method of social simulation model primarily focusing on an inter-organizational decision-making and demonstrates a configuration method for this simulation model using case studies on long-term economic growth model with technological change.
\end{abstract}

Keywords Simulation model $\cdot$ PDCA cycle $\cdot$ Decision making $\cdot$ Replicator dynamics $\cdot$ Inter-system control

JEL Classification C63 - E27 · M10

\section{A point of view for social simulation modeling}

\subsection{A replicator dynamics as a method of configuring evolutionary economic process and practical decision-making on business}

Decision-making, whether by organizations or individuals, is configured from diverse evaluation axes. The behavior of organizations and individuals arises from a bundle of such decision-making. The model in this paper is a micro-agent-based model, whether the agent is an organization or an individual, which is configured using one replicator dynamics for each decision-making behavior. Each replicator

Shungo Sakaki

sakaki@stf.teu.ac.jp

1 Tokyo University of technology, 1404-1, Katakura, Hachioji, Tokyo 192-8580, Japan 
dynamics is a unit making one decision. This paper describes a method of social simulation model primarily focusing on an inter-organizational decision-making.

On the other hand, there could be controversial issues against the use of replicator dynamics as the agent-based model that it is too simple and preliminary to depict industrial organizations and macroeconomic system. First, replicator dynamics mainly investigates selection issues while the mutations are not addressed at all. That is to say, the replicator dynamics describes selection only, no drift and no mutation. It is true, but a factor of mutation can be embedded in a model by other ways.

From a macroscopic point of view, we may certainly observe a phenomenon of mutation in such an evolutionary process as a society or economic system. However, a phenomenon of mutation in society or economic system cannot simply attribute to genetic miscopying or randomness in biology but can be derived from complex "path-dependency" on previous activities. For example, let us consider the problem of economic growth with technological change, which is a typical evolutionary process.

Dosi and Orsenigo (1988) argue that innovation is generally dominated by unintended results or uncertainty brought by the decision-making of an alien object with diverse technical capabilities, expectations, and beliefs. In other words, the existence of "events (world status)" to be aimed at by innovation is not fixed, but often must be recognized as a "non-stationary" existence that cannot be separated from the action of an activity object and is endogenously given.

Dosi (1990) says that the problems that need to be solved before implementing innovation activities are not only the renewal of methodologies or knowledge, which is required for the implication but also the dependency on problem settings in implementing the innovation itself. These problem settings depend on the technical capability and knowledge stored by an activity object. In this sense, innovation activity itself distinctively becomes "path-dependent" on previous activities and takes on a non-stationary characteristic.

In the sense mentioned above, it is virtually impossible to predict a phenomenon of mutation, that is, what kind of new technology can find practical application in the future or which technology becomes commercially practical in what area. Accordingly, it is impossible to determine the most appropriate allocation of R\&D investments by specifying individual areas.

Although it is difficult to specify an investment area, it is possible to address this problem as an economic resource allocation issue under the presumption that mutations should occur. That is, we can consider how to contribute more to the sustainable growth of companies or the entire national economic system as described below by setting the ratio between investments in extending existing (well known) technology and investments in changing to totally new (unknown) technology. As a result, we can manage an economic balance between selection and mutation in the context of sustainable growth.

This paper attempts to configure a method for modeling social and economical system associated with the evolutionary process as a resource allocation problem using a replicator dynamics. In other words, it models the evolutionary economic process in which both an occurrence and diffusion of a new phenomenon (mutation and selection) take place continuously and are implemented in a system where two 
alternative phases $A$ and $B$ are alternately selected over time. We suppose that phase $A$ has occurred when its diffusion rate becomes infimum over time.

Second, Cantner et al. (2016) point out that the pure model of replicator dynamics, though providing important insights in the evolution of markets, has not found much of empirical support such as the so-called "adverse selection". They developed an extended replicator dynamics model to analyze the market share changes of firms vertically integrated into value chains and succeeded to show several propositions. For example, they concluded in proposition 2 as follows:

"The average fitness in upstream layers of a value chain can increase rather than decrease over time if upstream firms that are less fit than the average of the market they are operating in are linked to highly fit partners in downstream layers of the value chain. This dynamics violates the predictions of the standard replicator dynamics model and can be considered a regressive development of market selection driven by value chain relations."

But adverse selection phenomena in the market, as well as natural selection, can also be commonly occurred in a replicator dynamics model based on a coordination game with very simple settings dependent on initial values, counterpart agent's preferences, transaction relations and so on. Therefore, in this paper, we adopt replicator dynamics model because of producing and depicting diverse phenomena or state transitions and of its fitness for practical decision-making on business, as described below.

\subsection{A way of thinking for practical decision-making on business}

Generally, decision-making in economics model is supposed to be configured under rational expectations, whether bounded rationality or perfect foresight. Accordingly, a general equilibrium state is supposed to exist where transactions are all balanced. On the contrary, practical decision-making on business, for example, is executed based on PDCA (Plan, Do, Check and Action) cycle. That is,

1. Collection, compilation and analysis of information on macroeconomy, industry (counterparties and competitors) and internal accounts.

2. Planning based on the above evidence.

3. Selection of plans based on feasibility and profitability.

4. Execution of the optimum plan at the concerned time.

5. Comparison between the forecast and actual achievement of the plan.

6. Modification of the plan.

The above process on PDCA cycle can be based on rational activity where the most profitable and therefore optimum plan is selected of the possible ones at the concerned time. But it is almost difficult theoretically and computationally to configure the process approaching the general equilibrium based on the practical PDCA cycle by each concerned agent.

On the contrary, we can propose the activity hypothesis that the relation between each practical decision making on business and the whole system (market 
mechanism and macroeconomy) can be configured through the actions where each decision-making agent on PDCA cycle adapts to the business environment as a whole system. A replicator dynamics, which the model covered in this paper is based on, can be consistent with the adaptive decision-making.

\subsection{An outline for configuration procedure of replicator dynamics}

In this section, we demonstrate the configuration procedure where the action based on a series of PDCA cycle is constructed using replicator dynamics as in Table 1.

The first stage configures a social organization such as a corporate organization or inter-corporate relations for a virtual system composed of (1) agent, (2) field and (3) interaction.

In the second stage, we define strategies that agents select as demonstrated above. Both strategies " $P 1, P 2, \ldots, P n$ " and " $Q 1, Q 2, \ldots, Q m$ ", which each agent select, respectively, can be planned based on the research results at the concerned time. Newly setting ups and abolitions of strategies can be approached whereby selection rates of strategies are varied from zero to a positive value or positive to zero, respectively, only if all the possible strategies are supposed in advance.

The third stage configures payoffs, respectively, based on each strategy of the party concerned and counterparties as demonstrated above. A state transition can be embedded into the payoff configuration over time.

In the fourth stage, we can summarize the above three-stage procedures using the following payoff matrix (see Table 2).

In the fifth stage, we can define replicator dynamics according to the above payoff matrix. Generally, replicator dynamics assumes a well-mixed population with a finite number of strategies and posits that the per capita growth rate of each strategy is proportional to its fitness. The state transitions of each strategy can be configured

Table 1 Summary of configuration procedure on PDCA cycle using replicator dynamics

\begin{tabular}{|c|c|}
\hline Stage & Stage description \\
\hline First stage & $\begin{array}{l}\text { System configuration } \\
\text { (1-1) Agent as individuals, internal divisions, corporations and so on } \\
\text { (1-2) Relations: competition, transaction and so on }\end{array}$ \\
\hline Second stage & $\begin{array}{l}\text { Strategy planning } \\
\text { (2-1) Strategies which counterparties select are assumed to be " } Q 1, Q 2, \ldots, Q m \text { " } \\
\text { based on the research at the concerned time } \\
\text { (2-2) Strategies the party concerned can plan and select at the concerned time are } \\
\text { assumed to be " } P 1, P 2, \ldots, P n "\end{array}$ \\
\hline Third stage & $\begin{array}{l}\text { Payoff definition } \\
\text { (3-1) Payoffs are defined as }(U, V) \text {, respectively, according to the combination of } \\
\text { strategies which the party concerned and counterparties select } \\
\text { (3-2) Inter-organizational relations such as competitive and complementary nature can } \\
\text { be configured based on the above payoff relations }\end{array}$ \\
\hline Fourth stage & Payoff matrix \\
\hline Fifth stage & Replicator dynamics \\
\hline
\end{tabular}


Table 2 Payoff matrix

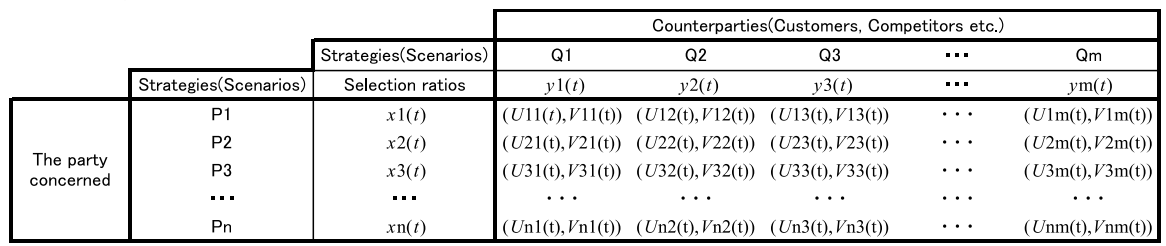

as population dynamics where each agent selects the concerned strategies over time. The selection ratios of each strategy in the whole system are equivalent to the population ratios of the agents that adopt the concerned strategy.

\subsection{An outline for configuration procedure of social simulation model}

The model covered in this paper is configured from a combination of multiple replicator dynamics, whereby a state transition of each decision is made using the respective replicator dynamics. Through the model in this paper, it is possible in principle to uniformly describe all decision-making from the decision-making of individuals, which consists of a bundle of diverse decision-making, to the organizational decision-making, such as corporate organizations and the national economy consisting of many agents.

This paper will configure a general-purpose simulation model for collective decision-making such as social or organizational one through the following three-stage procedure.

Stage 1 Replicator dynamics as the basis for decision-making.

Stage 2 Indirect control among replicator dynamics through the cross-reference of payoffs: interests in them.

Stage 3 Control between the systems configured using multiple replicator dynamics.

In indirect control model of Stage 2, each agent behaves based on its own decision-making, and the relationship among agents is mutually autonomous. In terms of social system, the model is configured as a laissez-faire market system so to speak.

It is, however, also possible to embed control functions based on some kind of value standards between the systems configured using multiple replicator dynamics. These are the corporate planning departments in corporate organizations and correspond to the policymaking departments of government, etc., in the macroeconomy. This Stage 3 model is the general-purpose model that is the objective of this paper. This paper presents this three-stage model configuration method in the following sections and case studies in the Appendices based on Sakaki (2004a). 


\section{Basic structure of decision-making: replicator dynamics}

Generally, replicator dynamics describes the relationship, whereby $n$ types of agent " $j$ " directly affect each other while making decisions out of $m_{j}$ types of alternative, respectively. A state transition, called the ratio of adoption of $m_{j}$ types of alternative, is derived from replicator dynamics. This selection ratio is an interpretation called the mixed strategy of the players in game theory but corresponds to the state of organizational and social selection in replicator dynamics, which is the dynamics of the agent group. Especially in the case of inter-system control explained later, direct policy interpretation is possible about the state of system selection.

In the replicator dynamics that form the basis for the model in this paper, the number of types is limited to two types of agent and two types of alternative, without losing generality in relation to the model configuration. In other words, the definition is based on

1. the interdependence between two different agents $X$ and $Y$; and

2. two alternatives (strategies) $A$ and $B$ that each agent could adopt.

By deriving a collective choice from individual decision-making through this replicator dynamics and by creating a complex of micro replicator dynamics, a social system can be formed. In other words, the general-purpose simulation model configured in this paper will be built as an integrated system for social and collective decision-making, based on replicator dynamics consisting of these basic constituent elements, via the following stages:

1. indirect control through the cross-reference of payoffs between agents;

2. the configuration of multiple systems using multiple replicator dynamics; and

3. control between each of the above systems.

This section will introduce the basic configuration of replicator dynamics based on the above problem statement. Let us start using $U_{t}$ to represent the payoff of agent $X$, which is one of the groups of parties, at time $t$ and using $V_{t}$ to represent the payoff of the other group $Y$. Furthermore, we will define the payoff that each agent will obtain if it adopts alternatives $A$ and $B$ according to the alternatives $A$ and $B$ of the counterparty. Let us make the left side of the superscript express the selection outcome of $X$ and the right side express the selection outcome of $Y$. For example, the payoff that agent $X$ will obtain if it chooses $A$ is defined as follows according to the alternatives $A$ and $B$ of counterparty $Y$.

$$
U_{t}^{A A}, U_{t}^{A B}
$$

Alternatively, the payoff that party $Y$ will obtain if it chooses $A$ can be defined as follows according to the alternatives $A$ and $B$ of counterparty $X$.

$$
V_{t}^{A A}, V_{t}^{B A}
$$


Table 3 Payoff matrix of agents $X$ and $Y$

\begin{tabular}{lll}
\hline$X / Y$ & $A$ & $B$ \\
\hline$A$ & $\left(U_{t}^{A A}, V_{t}^{A A}\right)$ & $\left(U_{t}^{A B}, V_{t}^{A B}\right)$ \\
$B$ & $\left(U_{t}^{B A}, V_{t}^{B A}\right)$ & $\left(U_{t}^{B B}, V_{t}^{B B}\right)$ \\
\hline
\end{tabular}

The matrix in Table 3 expresses the payoffs that can be defined from all the interrelationships between the above two groups.

Next, based on the payoff matrix in Table 3, let us try to configure replicator dynamics. Now, let us assume that $X$ and $Y$ are each configured as groups consisting of agents that could adopt the two alternatives $A$ and $B$. We then express the agents that adopt alternative $A$ at a certain time $t$ as a ratio to the total populations of $X$ and $Y$, respectively, as $x_{t}$ and $y_{t}$. Since there are two types of behavior the agents could choose, the population ratio of agents that adopt $B$ can be expressed as $1-x_{t}$ and $1-y_{t}$, respectively.

If we then use $E\left(U_{t}^{A}\right)$ and $E\left(U_{t}^{B}\right)$, respectively, to represent the expected payoff that agents belonging to Group $X$ will obtain if they adopt alternative $A$ or $B$, we are able to express them, respectively, as an average payoff in proportion to its population ratio of agents belonging to the counterparty Group $Y$ that adopt each alternative.

$$
\begin{aligned}
& E\left(U_{t}^{A}\right)=y_{t} U_{t}^{A A}+\left(1-y_{t}\right) U_{t}^{A B} \\
& E\left(U_{t}^{B}\right)=y_{t} U_{t}^{B A}+\left(1-y_{t}\right) U_{t}^{B B}
\end{aligned}
$$

The total payoff that agents belonging to Group $X$ can expect on average through alternatives $A$ and $B$ at this time: $E\left(U_{t}\right)$ can be expressed by averaging the expected payoffs: $E\left(U_{t}^{A}\right)$ and $E\left(U_{t}^{B}\right)$ using population ratios $x_{t}$ and $1-x_{t}$, which are the respective selection ratios of Group $X$ itself.

$$
\begin{aligned}
E\left(U_{t}\right) & =x_{t} E\left(U_{t}^{A}\right)+\left(1-x_{t}\right) E\left(U_{t}^{B}\right) \\
& =x_{t}\left\{y_{t} U_{t}^{A A}+\left(1-y_{t}\right) U_{t}^{A B}\right\}+\left(1-x_{t}\right)\left\{y_{t} U_{t}^{B A}+\left(1-y_{t}\right) U_{t}^{B B}\right\} \\
& =x_{t} y_{t} U_{t}^{A A}+x_{t}\left(1-y_{t}\right) U_{t}^{A B}+\left(1-x_{t}\right) y_{t} U_{t}^{B A}+\left(1-x_{t}\right)\left(1-y_{t}\right) U_{t}^{B B}
\end{aligned}
$$

Generally, replicator dynamics assumes a well-mixed population with a finite number of strategies as mentioned above and posits that the per capita growth rate of each strategy is proportional to its fitness. Thus, using the above result, the population dynamics of the group of agents belonging to Group $X$ that adopt alternative A can be defined as shown below (Weibull 1995). In other words, the state transition of the population ratio of the group adopting alternative $A$ is defined based on and proportional to the ratio of expected payoff in the case of adoption of alternative $A$ to total average payoff.

$$
\frac{x_{t+1}}{x_{t}}=\frac{E\left(U_{t}^{A}\right)}{E\left(U_{t}\right)}=\frac{y_{t} U_{t}^{A A}+\left(1-y_{t}\right) U_{t}^{A B}}{x_{t} y_{t} U_{t}^{A A}+x_{t}\left(1-y_{t}\right) U_{t}^{A B}+\left(1-x_{t}\right) y_{t} U_{t}^{B A}+\left(1-x_{t}\right)\left(1-y_{t}\right) U_{t}^{B B}}
$$




$$
x_{t+1}=\frac{x_{t} y_{t} U_{t}^{A A}+x_{t}\left(1-y_{t}\right) U_{t}^{A B}}{x_{t} y_{t} U_{t}^{A A}+x_{t}\left(1-y_{t}\right) U_{t}^{A B}+\left(1-x_{t}\right) y_{t} U_{t}^{B A}+\left(1-x_{t}\right)\left(1-y_{t}\right) U_{t}^{B B}}
$$

Similarly, expected payoff to be obtained by agents belonging to Group $Y$ if they adopt alternative $A$ or $B: E\left(V_{t}^{A}\right)$ and $E\left(V_{t}^{B}\right)$, the total average payoff: $E\left(V_{t}\right)$, and the population dynamics of the group that adopts alternative $A$ can each be expressed as follows:

$$
\begin{aligned}
& E\left(V_{t}^{A}\right)=x_{t} V_{t}^{A A}+\left(1-x_{t}\right) V_{t}^{B A} \\
& E\left(V_{t}^{B}\right)=x_{t} V_{t}^{A B}+\left(1-x_{t}\right) V_{t}^{B B} \\
& E\left(V_{t}\right)=y_{t} E\left(V_{t}^{A}\right)+\left(1-y_{t}\right) E\left(V_{t}^{B}\right) \\
& =y_{t}\left\{x_{t} V_{t}^{A A}+\left(1-x_{t}\right) V_{t}^{B A}\right\}+\left(1-y_{t}\right)\left\{x_{t} V_{t}^{A B}+\left(1-x_{t}\right) V_{t}^{B B}\right\} \\
& =y_{t} x_{t} V_{t}^{A A}+y_{t}\left(1-x_{t}\right) V_{t}^{B A}+\left(1-y_{t}\right) x_{t} V_{t}^{A B}+\left(1-y_{t}\right)\left(1-x_{t}\right) V_{t}^{B B} \\
& \frac{y_{t+1}}{y_{t}}=\frac{E\left(V_{t}^{A}\right)}{E\left(V_{t}\right)}=\frac{x_{t} V_{t}^{A A}+\left(1-x_{t}\right) V_{t}^{B A}}{y_{t} x_{t} V_{t}^{A A}+y_{t}\left(1-x_{t}\right) V_{t}^{B A}+\left(1-y_{t}\right) x_{t} V_{t}^{A B}+\left(1-y_{t}\right)\left(1-x_{t}\right) V_{t}^{B B}} \\
& y_{t+1}=\frac{y_{t} x_{t} V_{t}^{A A}+y_{t}\left(1-x_{t}\right) V_{t}^{B A}}{y_{t} x_{t} V_{t}^{A A}+y_{t}\left(1-x_{t}\right) V_{t}^{B A}+\left(1-y_{t}\right) x_{t} V_{t}^{A B}+\left(1-y_{t}\right)\left(1-x_{t}\right) V_{t}^{B B}}
\end{aligned}
$$

If the interdependence of transactions between the groups is defined as shown in Table 3 and the payoffs shown in the matrix are defined concretely through the above process, the ratio of behavior selection adopted over time by each group can be found as population dynamics.

Replicator dynamics as a unit of micro decision-making is based on adaptive behavior theory in relation to the behavior selection of the direct counterparty, as seen above. For example, a typical example of decision-making by companies is management plans, such as plans for the next fiscal year, medium-term plans and long-term plans covering capital investment. All management plans involve drawing up an initial plan based on forecasts and estimates, reviewing the plan as the plan progresses in light of the movement in competitors, the external macroeconomic environment, and other factors, and reformulating a revised plan, etc. In addition, in the case of day-to-day decision-making related to profit and loss during the period, managers always compare previous budgets and plan with actual results and revise the plan where necessary. In this way, adaptive decision-making behavior takes place based on a PDCA cycle at every level from day-to-day decision-making to 
long-term management plans. The principles of decision-making through replicator dynamics are consistent with decision-making in practice.

\section{Indirect control among replicator dynamics through cross-reference of payoffs}

According to Deguchi (2000), rather than simply describing the interaction that depends directly on the population ratio of each agent, which is the definitional equation of replicator dynamics, it is now possible to configure the relationship, whereby agents indirectly affect each other by cross-referencing information concerning the payoff structure. Through this system configuration called indirect control, it became possible to describe the relationship among multiple replicator dynamics as well, and the application domain expanded dramatically. ${ }^{1}$ This is because even if agents are not directly affected through the decision-making of other agents, generally they are affected by each other through competition to acquire payoffs.

Let us try looking at the next system consisting of replicator dynamics. These are Eqs. (4') and (8') for the replicator dynamics of Groups $X$ and $Y$ described in Sect. 2 (reproduced), and Eq. (9) for new Group Z. Group $Z$ is configured such that decision-making is made within a group consisting of the same type of agents unlike the decision-making between different agents such as Groups $X$ and $Y$. As before, there are two types of decision-making alternatives $A$ and $B$. In addition, since Group $Z$ is a homogeneous group, the payoffs in the case of differing alternatives between agents are symmetric, and $W^{A B}=W^{B A}$.

$$
\begin{gathered}
x_{t+1}=\frac{x_{t} y_{t} U_{t}^{A A}+x_{t}\left(1-y_{t}\right) U_{t}^{A B}}{x_{t} y_{t} U_{t}^{A A}+x_{t}\left(1-y_{t}\right) U_{t}^{A B}+\left(1-x_{t}\right) y_{t} U_{t}^{B A}+\left(1-x_{t}\right)\left(1-y_{t}\right) U_{t}^{B B}} \\
y_{t+1}=\frac{y_{t} x_{t} V_{t}^{A A}+y_{t}\left(1-x_{t}\right) V_{t}^{B A}}{y_{t} x_{t} V_{t}^{A A}+y_{t}\left(1-x_{t}\right) V_{t}^{B A}+\left(1-y_{t}\right) x_{t} V_{t}^{A B}+\left(1-y_{t}\right)\left(1-x_{t}\right) V_{t}^{B B}} \\
z_{t+1}=\frac{z_{t}^{2} W_{t}^{A A}+z_{t}\left(1-z_{t}\right) W_{t}^{A B}}{z_{t}^{2} W_{t}^{A A}+z_{t}\left(1-z_{t}\right) W_{t}^{A B}+z_{t}\left(1-z_{t}\right) W_{t}^{A B}+\left(1-z_{t}\right)^{2} W_{t}^{B B}}
\end{gathered}
$$

\footnotetext{
${ }^{1}$ In replicator dynamics, as shown in the payoff matrix in the previous section, the relationship between the agents is assumed to be an interaction through random matching. But Deguchi (2000) succeeded in reconfiguring this as learning dynamics relating to the attitude change of the alternatives of each agent using the Markov process, which configures the adoption of alternatives in replicator dynamics as transition probability, as a basis. In this event, the configuration equation for replicator dynamics presented in the previous section was not affected at all and a new interpretation was given by reconfiguration through the Markov process. As a result, replicator dynamics was freed from the restrictions of the random matching assumption, which had become a bottleneck in the economic phenomenon application domain.
} 
Equations (4') and ( $\left.8^{\prime}\right)$ for the replicator dynamics of Groups $X$ and $Y$ mutually depend directly on the population ratios of the agents that belong to $X$ and $Y$. Let us note, however, that Eq. (9) for Group $Z$ directly depends on the population ratio of agents that belong to Group $Z$ only. In other words, Eqs. (4'), ( $\left.8^{\prime}\right)$ and (9) do not mutually depend directly on the population ratios of each other and the definition of replicator dynamics is not valid between these three equations. Equations $\left(4^{\prime}\right),\left(8^{\prime}\right)$ and (9) are independent replicator dynamics, respectively.

However, with the indirect control expounded by Deguchi (2000), it became possible to configure a system having relationships through common variables within the payoff configuration of Eqs. (4'), (8') and (9), and enabling practical interpretation. For example, if a relationship whereby each payoff depended on each of the population ratios:

$$
U_{t}\left(x_{t}, y_{t}, z_{t}\right), V_{t}\left(x_{t}, y_{t}, z_{t}\right), W_{t}\left(x_{t}, y_{t}, z_{t}\right),
$$

could be defined, interdependence between Eqs. (4'), ( $\left(^{\prime}\right)$ and (9) would arise through their respective population ratios and this would indirectly affect the state transition of each population ratio.

\section{Inter-system control}

The model of indirect control in Sect. 3 configured a relationship between systems, whereby multiple replicator dynamics indirectly affect each other by cross-referencing information concerning the payoff structure. Any of agents then behave based on their own decision-making, and their relationship is configured as a mutually autonomous laissez-faire market system so to speak.

It is, however, also possible to embed direct control functions based on some kind of value standards among the systems configured using multiple replicator dynamics. These are the business planning departments in corporate organizations and correspond to the policymaking departments such as government in the national economy. With significant progress in information network technologies, the gathering, compiling, analyzing and distribution functions of the information necessary for such control have improved dramatically, and the possibility has emerged that the mechanisms, which achieve control or inducement among systems, can be realistically organized.

And so to configure the mechanisms of inter-system control, let us consider multiple virtual systems. Let the virtual systems be replicator dynamics configured as social systems, whereby the configurations of agents are the same but elements such as the payoff configuration and/or interdependence relations are different. We then define the aggregate value per capita to be generated using a configuration equation that is common to these multiple virtual systems. Using this as a standard measure, we control the existence ratio of each system through "the third replicator dynamics", which selects the multiple virtual systems. The inter-system control is a system design model combining the merits of each virtual social system according to these existence ratios based on such an idea. This paper will consider control of the system in which the two virtual systems are two opposite extreme alternatives. 
As seen in Sect. 2, generally, the replicator dynamics of a group consisting of two different types of an agent can be expressed using the following equations (Reproduced). Each of the equations is configured from the population ratios at the beginning of the period of the two types of groups $X$ and $Y: x_{t}$ and $y_{t}$ and each of their payoffs. And since the payoffs themselves also depend on the population ratios of the two types of the group at the beginning of the period, this means that the replicator dynamics of each group can consequently be expressed using functions of the population ratios of the two types of the group at the beginning of the period.

$$
\begin{aligned}
& \frac{x_{t+1}}{x_{t}}=\frac{E\left(U_{t}^{A}\right)}{E\left(U_{t}\right)}=\frac{y_{t} U_{t}^{A A}+\left(1-y_{t}\right) U_{t}^{A B}}{x_{t} y_{t} U_{t}^{A A}+x_{t}\left(1-y_{t}\right) U_{t}^{A B}+\left(1-x_{t}\right) y_{t} U_{t}^{B A}+\left(1-x_{t}\right)\left(1-y_{t}\right) U_{t}^{B B}} \\
& \frac{y_{t+1}}{y_{t}}=\frac{E\left(V_{t}^{A}\right)}{E\left(V_{t}\right)}=\frac{x_{t} V_{t}^{A A}+\left(1-x_{t}\right) V_{t}^{B A}}{y_{t} x_{t} V_{t}^{A A}+y_{t}\left(1-x_{t}\right) V_{t}^{B A}+\left(1-y_{t}\right) x_{t} V_{t}^{A B}+\left(1-y_{t}\right)\left(1-x_{t}\right) V_{t}^{B B}}
\end{aligned}
$$

So let us try rewriting Eqs. (4) and (8) for the replicator dynamics of groups $X$ and $Y$ consisting of two different types of agents as functions of the population ratios at the beginning of the period of the two types of groups: $x_{t}$ and $y_{t}$. And we will distinguish the population ratios between the two virtual social systems consisting of the same group configuration, in other words, each system using the superscript 0 and 1, respectively. The replicator dynamics (10) and (11) are for the virtual social system " 0 ", and (12) and (13) are for the virtual social system " 1 ". The functional types of $f, F, g$, and $G$ will be different between systems " 0 " and " 1 ", respectively, due to the configuration of payoffs, etc,

$$
\begin{aligned}
& \left\{\begin{array}{l}
\frac{x_{t+1}^{0}}{x_{t}^{0}}=\frac{E\left(U_{t}^{A}\right)}{E\left(U_{t}\right)} \equiv \frac{f^{0}\left(x_{t}^{0}, y_{t}^{0}\right)}{F^{0}\left(x_{t}^{0}, y_{t}^{0}\right)} \\
\frac{y_{t+1}^{0}}{y_{t}^{0}}=\frac{E\left(V_{t}^{A}\right)}{E\left(V_{t}\right)} \equiv \frac{g^{0}\left(x_{t}^{0}, y_{t}^{0}\right)}{G^{0}\left(x_{t}^{0}, y_{t}^{0}\right)}
\end{array}\right. \\
& \left\{\begin{array}{l}
\frac{x_{t+1}^{1}}{x_{t}^{1}}=\frac{E\left(U_{t}^{A}\right)}{E\left(U_{t}\right)} \equiv \frac{f^{1}\left(x_{t}^{1}, y_{t}^{1}\right)}{F^{1}\left(x_{t}^{1}, y_{t}^{1}\right)} \\
\frac{y_{t+1}^{1}}{y_{t}^{1}}=\frac{E\left(V_{t}^{A}\right)}{E\left(V_{t}\right)} \equiv \frac{g^{1}\left(x_{t}^{1}, y_{t}^{1}\right)}{G^{1}\left(x_{t}^{1}, y_{t}^{1}\right)}
\end{array}\right.
\end{aligned}
$$


Next, let us define the aggregate value per capita produced in society as a whole. This value is configured as a measure that is common to virtual social systems " 0 " and " 1 ". The configuration procedure (calculation formula) for the aggregate value per capita is the same, but due to differences of the population ratios in the configured virtual social systems, each value at the relevant point in time will be different.

$$
\begin{aligned}
& h\left(x_{t}^{0}, y_{t}^{0}\right) \\
& h\left(x_{t}^{1}, y_{t}^{1}\right)
\end{aligned}
$$

With this aggregate value per capita as the evaluation standard, and using the virtual social systems " 0 " and " 1 " as two opposite extreme alternatives, let us consider the sector that determines the selection ratios: the system control sector. The system control sector is configured of groups consisting of the same type of agents, which select the two virtual social systems. Then, with aggregate value per capita as the evaluation standard, if we use virtual social systems " 0 " and " 1 " to represent each of the alternatives and use $\rho_{t}^{0}$ to represent the population ratio of agents that select the former system and $\rho_{t}^{1}$ to represent the population ratio of agents that select the latter, we can define the following replicator dynamics:

$$
\begin{aligned}
& \rho_{t+1}^{0}=\frac{\left(\rho_{t}^{0}\right)^{2} h\left(x_{t}^{0}, y_{t}^{0}\right)+\rho_{t}^{0} \rho_{t}^{1} h\left(x_{t-1}^{0}, y_{t-1}^{0}\right)}{\left(\rho_{t}^{0}\right)^{2} h\left(x_{t}^{0}, y_{t}^{0}\right)+\rho_{t}^{0} \rho_{t}^{1} h\left(x_{t-1}^{0}, y_{t-1}^{0}\right)+\rho_{t}^{1} \rho_{t}^{0} h\left(x_{t-1}^{1}, y_{t-1}^{1}\right)+\left(\rho_{t}^{1}\right)^{2} h\left(x_{t}^{1}, y_{t}^{1}\right)} \\
& \rho_{t+1}^{1}=\frac{\left(\rho_{t}^{1}\right)^{2} h\left(x_{t}^{1}, y_{t}^{1}\right)+\rho_{t}^{1} \rho_{t}^{0} h\left(x_{t-1}^{1}, y_{t-1}^{1}\right)}{\left(\rho_{t}^{1}\right)^{2} h\left(x_{t}^{1}, y_{t}^{1}\right)+\rho_{t}^{1} \rho_{t}^{0} h\left(x_{t-1}^{1}, y_{t-1}^{1}\right)+\rho_{t}^{0} \rho_{t}^{1} h\left(x_{t-1}^{0}, y_{t-1}^{0}\right)+\left(\rho_{t}^{0}\right)^{2} h\left(x_{t}^{0}, y_{t}^{0}\right)}
\end{aligned}
$$

$$
\rho_{t}^{0}+\rho_{t}^{1}=1
$$

In the system control sector, as in the research and development sector in Appendix 2, for agents adopting each alternative, the existence of agents adopting the same alternative affects average payoff. If the groups of agents belonging to the system control sector make the same judgment on the virtual social system to be selected, the aggregate value per capita of this system in the "current period" is used as the evaluation standard. Because they can calculate "the aggregate value for this term" as they can share the same information on the current term relating to the selection ratio of knowledge stocks chosen in the groups $X$ and $Y$.

However, if they make different judgments on the virtual social system to be selected, the aggregate value per capita in the "previous period" is used as the evaluation standard. Because in this situation, only the already known "aggregate value 
for the previous term" can be calculated as they cannot share information on the current term. $^{2}$

The aggregate value per capita in each of these periods is produced based on the population ratios in each period, respectively. In addition, since there are two types of virtual social system as alternatives, the sum total of the population ratios of the groups in the system control sector that choose both is 1 as shown in Eq. (18).

Then, if the selection ratios of the two virtual social systems are determined by Eqs. (16) and (17), we can define a state transition in decision-making in the real society. This real society can be induced to be controlled into the more desirable state based on the aggregate value per capita standard. The numerator, which expresses the average payoff if both agents $X$ and $Y$ adopt one of the alternatives, and the denominator, which expresses the average payoff through both alternatives, are, in both equations, average values calculated through the two virtual social system selection ratios, and satisfy the definition configuration of replicator dynamics.

$$
\begin{aligned}
& \frac{x_{t+1}}{x_{t}}=\frac{\rho_{t}^{0} f^{0}\left(x_{t}, y_{t}\right)+\rho_{t}^{1} f^{1}\left(x_{t}, y_{t}\right)}{\rho_{t}^{0} F^{0}\left(x_{t}, y_{t}\right)+\rho_{t}^{1} F^{1}\left(x_{t}, y_{t}\right)} \\
& \frac{y_{t+1}}{y_{t}}=\frac{\rho_{t}^{0} g^{0}\left(x_{t}, y_{t}\right)+\rho_{t}^{1} g^{1}\left(x_{t}, y_{t}\right)}{\rho_{t}^{0} G^{0}\left(x_{t}, y_{t}\right)+\rho_{t}^{1} G^{1}\left(x_{t}, y_{t}\right)}
\end{aligned}
$$

To sum up the above, the system of the general-purpose simulation model using inter-system control can be configured as a complex form of replicator dynamics (A), (B) and (C). And it guides real society using the distribution ratios obtained from simulation of the virtual systems: $\rho_{t}^{0}$ and $\rho_{t}^{1}$ as policy variables.

(A) Two virtual social system sectors: (10), (11) and (12), (13).

(B) System control sector: (16), (17).

(C) Real society sector: (19), (20).

\section{Concluding remarks}

This paper presented a method for the configuration of a social simulation model intended for general-purpose application as "inter-system control model" to analyze real societies engaged in complex and diverse decision-making. The author so far developed three types of simulation model applying the inter-system control concept to economic problems. These are "Management Model for Technological Change and Sustainable Growth (Sakaki 2004a)", "Model for Evaluation between Open Access and Reinforcing Private Ownership (Sakaki 2009)", and "Model for Income Distribution and Economic Growth (Sakaki 2017)".

\footnotetext{
2 The aggregate value per capita could also be set at 0 when the agents make different judgments. In this case, we interpret this situation as not sharing or appreciating the information on the previous term.
} 
Open Access This article is distributed under the terms of the Creative Commons Attribution 4.0 International License (http://creativecommons.org/licenses/by/4.0/), which permits unrestricted use, distribution, and reproduction in any medium, provided you give appropriate credit to the original author(s) and the source, provide a link to the Creative Commons license, and indicate if changes were made.

\section{Appendices}

These appendices demonstrate the outlines of case studies for Sects. 2, 3 and 4, which describe science technology policy that manages long-term economic growth through a technological change based on Sakaki (2004a) (refer this paper for details). They introduce models that express the process of S-shaped long-term economic growth configured from the creation of new technologies and the substitution of existing technologies in the alternation of two types of knowledge stocks over time, which are the source of technologies (Yoshikawa 2000). In other words, it models the process of sustainable economic growth in which technological change takes place continuously in a system where two alternative knowledge stocks $A$ and $B$ are alternately selected over time.

\section{Appendix 1: case study for Sect. 2-replicator dynamics}

This system is configured with two sub-sectors: Group $X$ consisting of business companies, and Group $Y$ consisting of financial institutions, as the private business sector. The private business sector has a decision-making system that accumulates knowledge stocks $A$ and $B$, which are the two alternatives, in each sub-sector, while selecting the "fields and domains" that are more productive. The standards for evaluating the productivity of this knowledge stock are total productivity and marginal productivity that knowledge stock generates. The evaluating agents are business companies whose behavior standard is total productivity and financial institutions whose behavior standard is marginal productivity.

Now, let us try configuring payoff structures in this case. ${ }^{3}$ First, the payoff of Group $Y$ (to which financial institutions belong), whose behavior standard is marginal productivity, is defined as follows based on the scarcity of the "fields and domains" of the knowledge stock being commercialized.

$$
\begin{gathered}
V_{t}^{A A}=\left(1-\frac{x_{t}+y_{t}}{2}\right)^{c} ; \quad c \geq 1 \\
V_{t}^{B B}=\left(1-\frac{\left(1-x_{t}\right)+\left(1-y_{t}\right)}{2}\right)^{c} ; \quad c \geq 1
\end{gathered}
$$

\footnotetext{
3 The following payoff configuration produces evolutionary growth model in which technological change takes place continuously [See Sakaki (2004b) and (2018) for detail].
} 
Each of these takes a value in the range 0-1. For example, Eq. (21) for the marginal product obtained if both the business companies and the financial institutions select $A$ is structured so that the closer the population ratios of both: $x_{t}$ and $y_{t}$, get to 0 , the more scarcity increases, and as a result, the marginal product takes a maximum value close to 1 . Conversely, the closer the population ratios of both get to 1 , the more the scarcity of the technology decreases and the technology becomes commonplace, and as a result, the marginal product drops to a minimum value 0 . And because of parameter $c$, the equation is structured so that the more the value of $c$ increases beyond 1 , the more a high marginal product is concentrated on a small number of agents. ${ }^{4}$

Next, the payoff of Group $X$ (to which business companies belong), whose behavior standard is total productivity, is configured as the total value corresponding to the accumulated value of each period's marginal product.

$$
\begin{aligned}
& U_{t}^{A A}=U_{t-1}^{A A}+V_{t}^{A A}=\sum_{\tau=0}^{t} V_{\tau}^{A A} ; U_{0}^{A A}=V_{0}^{A A} \\
& U_{t}^{B B}=U_{t-1}^{B B}+V_{t}^{B B}=\sum_{\tau=0}^{t} V_{\tau}^{B B} ; U_{0}^{B B}=V_{0}^{B B}
\end{aligned}
$$

Under the system, financial institutions engage in financial transactions with business companies that select the same "fields and domains" consisting of knowledge stocks $A$ and $B$. Financial institutions give finance to business companies in relation to such knowledge stock fields, and business companies pay to financial institutions the portion of the total production value obtained as a result of using these funds to engage in capital investment and production in such knowledge stock fields, which corresponds to the marginal product. The system selects and accumulates knowledge stocks $A$ and $B$ over time through financial transactions between business companies and financial institutions as outlined above. Based on the above configuration and the already described Eqs. (4) and (8), we can define the replicator dynamics for this system as follows:

$$
\begin{aligned}
& x_{t+1}=\frac{x_{t} y_{t} U_{t}^{A A}}{x_{t} y_{t} U_{t}^{A A}+\left(1-x_{t}\right)\left(1-y_{t}\right) U_{t}^{B B}} \\
& y_{t+1}=\frac{y_{t} x_{t} V_{t}^{A A}}{y_{t} x_{t} V_{t}^{A A}+\left(1-y_{t}\right)\left(1-x_{t}\right) V_{t}^{B B}}
\end{aligned}
$$

\footnotetext{
4 This paper assumes a skew distribution where a high amount of reward is to a degree concentrated on a few entities in the sense of Scherer (1999). In the simulation, the Scherer condition is set as $c=9.5$ in line with Sakaki (2004a, 2009, 2017).
} 

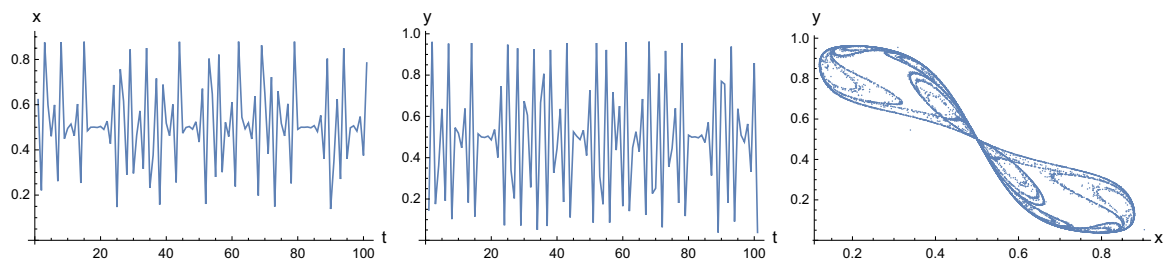

Fig. 1 Knowledge stock selection ratios of business companies: $X$ and financial institutions: $Y$. From the left and middle sides of the figure, knowledge stock selection ratios of business companies $X$ and financial institutions $Y$, respectively. The right side of the figure is scatter plot of both

This difference equation-type model has an inherent chaotic structure and this structure is an essential requirement necessary for long-term economic growth accompanied by technological change. This requirement corresponds to the introduction of a social system. That is, it is the system that fully depreciates the payoff valuation when two knowledge stocks $A$ and $B$ do not match on transactions between business companies and financial institutions. ${ }^{5}$ At this event, the system allows trial and error for technological development and supports a technological change in terms of the allocation of resources. ${ }^{6}$ This allocation of resources is the antithesis of the allocation of resources that promotes efficiency or dissemination in society. The trajectory of the replicator dynamics that expresses this system has a chaotic and fractal structure. ${ }^{7}$ Figure 1 is one example of the results of its numerical calculation.

\section{Appendix 2: case study for Sect. 3-indirect control among replicator dynamics}

Case studies on indirect control include, first, Deguchi (2000). It models the disintegration of social norms and the formation of order based on a prisoners' dilemma game. Sakaki (2015) also uses a similar model to design systems such as corrective education, publicly supported education and privately supported education through indirect control and to examine the possibility of the formation of order in social norms.

This appendix introduces the research and development sector in addition to the private business sector presented in the case study in Appendix 1. There are indirect control relationships through mutual reference to each payoff among these sectors.

Let us begin by finding the average of the two alternative knowledge stocks $A$ and $B$ according to the selection ratios of agents that belong to the research and development sector $Z$, and thereby considering average stock per capita throughout society

\footnotetext{
5 That is, $U_{t}^{A B}=U_{t}^{B A}=0$ and $V_{t}^{A B}=V_{t}^{B A}=0$.

${ }^{6}$ Information about the concepts relating to this social system has been introduced in Sect. 4 Inter-system control.

7 Generally, when the maximal Lyapunov exponent is positive, a figure that configures the attractor is considered to have a fractal structure. According to the results of the numerical calculations of the model in this paper, the maximal Lyapunov exponent $=0.421$, and when the embedding dimension is 8 , correlation dimension $\nu=1.315$ [for details, see Sakaki (2004b)].
} 
as a whole: $s_{t}$. We assume that in relation to this $s_{t}$, agents belonging to this sector select behavior consisting of three alternatives regarding knowledge stock renewal.

The first alternative is to completely renew existing average knowledge stock accumulated as of the beginning of the current period (end of the previous period): $s_{t}$ with new knowledge stock related to knowledge stock $A$. In other words, this alternative is to invest all this average stock in the R\&D of new knowledge stock related to knowledge stock $A$ and to obtain the return on this investment. We then express the population ratio of agents that adopt alternative $A$ to the total populations of $Z$, as $z_{t}^{A}$.

The second alternative is to invest all the average stocks: $s_{t}$ in the R\&D of new knowledge stock related to the other knowledge stock $B$ and to obtain the return on this investment. We then express the population ratio of the agents that adopt alternative $B$ to the total populations of $Z$, as $z_{t}^{B}$.

Finally, the third alternative is to keep the existing stock level as of the beginning of the period: $s_{t}$, without engaging in R\&D for the renewal of either knowledge stock $A$ or $B$. Since there are three types of behavior the agents could choose, the population ratio of agents that keep the existing stock level can be expressed as $1-z_{t}^{A}-z_{t}^{B}$.

Let us consider the case of investing all average knowledge stock per capita accumulated as of the beginning of the period: $s_{t}$ to generate new knowledge stocks $A$ and $B$, respectively. The source of the funds for research and development in this event is $s_{t}$ itself.

In relation to this source of funds, we consider the relationship, whereby the return on this R\&D investment depends on the population ratios of the R\&D agents that use each knowledge stock, respectively. In other words, the closer the population ratios at the beginning of the period $z_{t}^{A}$ and $z_{t}^{B}$ get to 0 , the more scarcity increases, resulting in a limitless expansion in the investment return. ${ }^{8}$ However, the closer the population ratios get to 1 , the more the commercial value of each knowledge stock deteriorates and the investment return becomes 0 . Further, we assume a similar relationship with the marginal product defined for the private business sector in Appendix 1, that is, Eqs. (21) and (22), because this sector benefits from the investment return.

From the above relationship, the gains obtained by renewing the average knowledge stock balance at the beginning of the period into the domains $A$ and $B$ are defined as $W_{t}^{A A}$ and $W_{t}^{B B}$, respectively, as follows. The parameter " $a$ " affects the scale of the R\&D results, and " $c$ " affects the degree of concentration of these results. Parameters " $a$ " and " $c$ " have the effect of controlling the degree to which high marginal productivity is concentrated on a small number of R\&D agents, respectively. ${ }^{9}$

$$
W_{t}^{A A}=s_{t}\left(\left(\frac{1}{z_{t}^{A}}\right)^{a}-1\right)\left(1-\frac{x_{t}+y_{t}}{2}\right)^{c} ; \quad a \geq 1, c \geq 1
$$

\footnotetext{
${ }^{8}$ On the other hand, the expectation value on this R\&D return increases as each population ratio of this sector gets to 1 as seen in replicator dynamics (29) and (30).

9 As in "Appendix 1", in the sense of Scherer (1999), we configure a skew distribution in which a high amount of reward is to a degree concentrated on certain entities by setting $a=1.8$ and $c=9.5$.
} 


$$
W_{t}^{B B}=s_{t}\left(\left(\frac{1}{z_{t}^{B}}\right)^{a}-1\right)\left(1-\frac{\left(1-x_{t}\right)+\left(1-y_{t}\right)}{2}\right)^{c} ; \quad a \geq 1, c \geq 1
$$

Based on the above configuration, we can define the equation for determining the change in the population ratios adopting each alternative using discrete-type replicator dynamics (Weibull 1995).

$$
\begin{aligned}
& z_{t+1}^{A}=\frac{\left(z_{t}^{A}\right)^{2} W_{t}^{A A}}{\left(z_{t}^{A}\right)^{2} W_{t}^{A A}+\left(z_{t}^{B}\right)^{2} W_{t}^{B B}+\left(1-z_{t}^{A}-z_{t}^{B}\right)^{2} s_{t}} \\
& z_{t+1}^{B}=\frac{\left(z_{t}^{B}\right)^{2} W_{t}^{B B}}{\left(z_{t}^{A}\right)^{2} W_{t}^{A A}+\left(z_{t}^{B}\right)^{2} W_{t}^{B B}+\left(1-z_{t}^{A}-z_{t}^{B}\right)^{2} s_{t}}
\end{aligned}
$$

Next, the private business sector's gains are redefined as follows. First, the marginal product, which is the gain of financial institutions, is found by multiplying Eqs. (21) and (22), which express scarcity in private business sectors, by the value corresponding to the results of the implementation of $R \& D$ (equal to the product obtained by multiplying the average value of the knowledge stock renewed in the R\&D sector $s_{t+1}$ by the R\&D investment ratio $z_{t}^{A}+z_{t}^{B}$ ).

$$
\begin{gathered}
V_{t}^{A A}=\left(z_{t}^{A}+z_{t}^{B}\right) s_{t+1}\left(1-\frac{x_{t}+y_{t}}{2}\right)^{c} ; \quad c \geq 1 \\
V_{t}^{B B}=\left(z_{t}^{A}+z_{t}^{B}\right) s_{t+1}\left(1-\frac{\left(1-x_{t}\right)+\left(1-y_{t}\right)}{2}\right)^{c} ; \quad c \geq 1
\end{gathered}
$$

Meanwhile, the gain of business companies is redefined as the value obtained by deducting $R \& D$ investment from the balance of each knowledge stock accumulated as of the beginning of the period and then substituting/adding the new marginal product. It is to be noted that there are indirect control relationships through mutual reference to each payoff among these sectors, (27), (28), (31), (32), (33) and (34).

$$
\begin{aligned}
& U_{t}^{A A}=\left(1-z_{t}^{A}-z_{t}^{B}\right) s_{t}^{A}+V_{t}^{A A} \\
& U_{t}^{B B}=\left(1-z_{t}^{A}-z_{t}^{B}\right) s_{t}^{B}+V_{t}^{B B}
\end{aligned}
$$

These population ratios in this sector: $z_{t}^{A}$ and $z_{t}^{B}$ represent the $\mathrm{R} \& \mathrm{D}$ ratio in relation to the knowledge stock $A$ and $B$, respectively. Figure 2 is an example of the numerical calculations. 

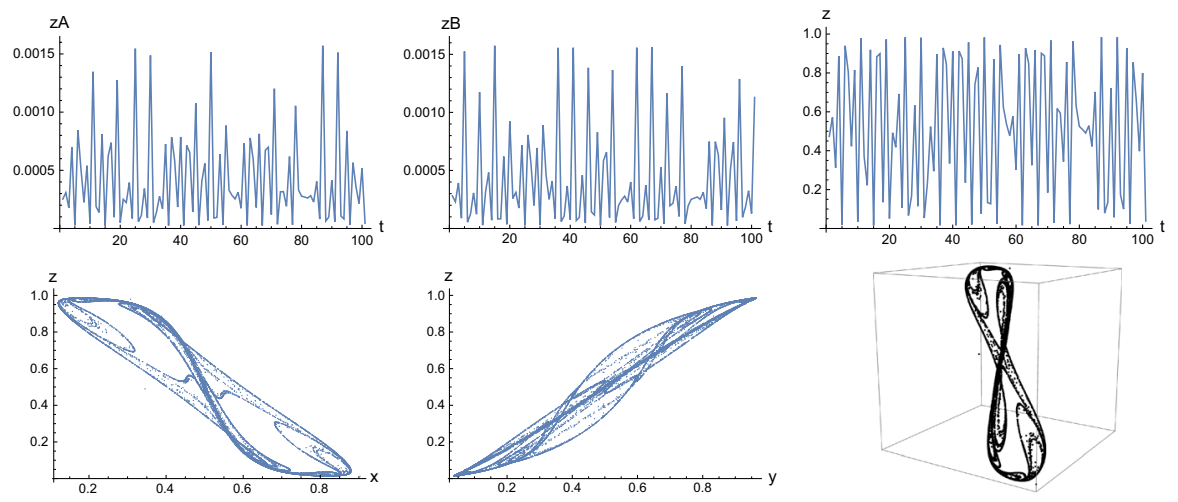

Fig. 2 Indirect control system. From top left and middle: R\&D ratios of knowledge stocks $A$ and $B$, respectively. Right shows the proportion of both. From bottom left and middle: scatter plots of business companies $X$ and R\&D sector $Z$, and financial institutions $Y$ and R\&D sector $Z$, respectively (scatter plot of $X$ and $Y$ is the same shape as the right side of Fig. 1). Bottom right is 3-D scatter plot of $X, Y$ and $Z$

\section{Appendix 3: case study for Sect. 4-inter-system control}

Finally, we will finish a social simulation model that we can construct and use as a social system introducing the inter-system control structures. In relation to the indirect control-type system configured with two sectors (research and development sector and private business sector) presented in Appendix 2, we will consider two virtual social systems. Furthermore, we will add the system control sector that controls these two virtual systems, and configure an inter-system control model consisting of complex-type replicator dynamics. Its structure can be expressed as shown in Fig. 3.

We construct two virtual social systems, in which the payoffs obtained in the previous period are fully evaluated or fully depreciated when two knowledge stocks $A$ and $B$ do not match on transactions between business companies and financial institutions. The latter system can be expressed as (25) and (26) in Appendix 1. On the other hand, the former system can be expressed as follows using Eqs. (4) and (8) in Sect. 2. It is to be noted that the previous period payoffs when two knowledge stocks $A$ and $B$ do not match are fully evaluated in the case of the former system, but on the other hand, they are fully depreciated in the case of the latter system.

$$
\begin{aligned}
& x_{t+1}=\frac{x_{t} y_{t} U_{t}^{A A}+x_{t}\left(1-y_{t}\right) U_{t-1}^{A A}}{x_{t} y_{t} U_{t}^{A A}+x_{t}\left(1-y_{t}\right) U_{t-1}^{A A}+\left(1-x_{t}\right) y_{t} U_{t-1}^{B B}+\left(1-x_{t}\right)\left(1-y_{t}\right) U_{t}^{B B}} \\
& y_{t+1}=\frac{y_{t} x_{t} V_{t}^{A A}+y_{t}\left(1-x_{t}\right) V_{t-1}^{A A}}{y_{t} x_{t} V_{t}^{A A}+y_{t}\left(1-x_{t}\right) V_{t-1}^{A A}+\left(1-y_{t}\right) x_{t} V_{t-1}^{B B}+\left(1-y_{t}\right)\left(1-x_{t}\right) V_{t}^{B B}}
\end{aligned}
$$




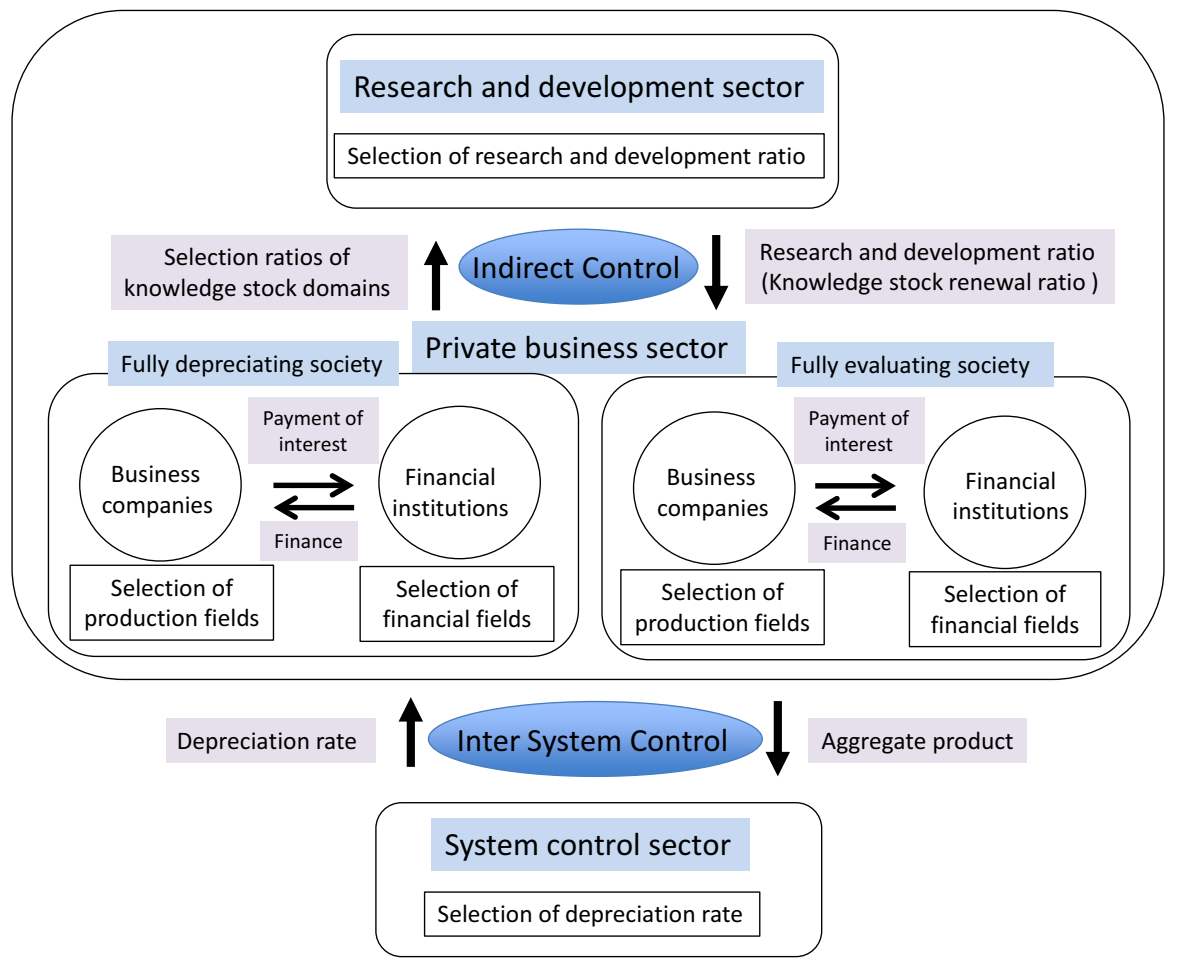

Fig. 3 Structure of inter-system control in sustainable growth model

The system control sector selects two these opposite extreme virtual social systems using aggregate output values per capita (e.g., GDP per capita), which are produced in each of systems, as the evaluation standard.

The aggregate outputs in the relevant system can be defined as follows. First, total products in each knowledge stock domain are defined as accumulated knowledge stock at the end of the previous period minus R\&D expenses in the current period, plus the marginal product in the current period based on the population ratio of business companies.

Next, the aggregate outputs are composed of the total products in each knowledge stock averaged by the population ratios of the private business sector. If business companies and financial institutions choose the same knowledge stock domains, the current period's total products in each domain are used to find the average, while in the case of different choices, the previous period's products in the domain chosen by business companies are assumed to be used.

$$
\begin{gathered}
\mathrm{TP}_{t}^{A}=\left(1-z_{t}^{A}-z_{t}^{B}\right) s_{t}^{A}+x_{t} V_{t}^{A A} \\
\mathrm{TP}_{t}^{B}=\left(1-z_{t}^{A}-z_{t}^{B}\right) s_{t}^{B}+\left(1-x_{t}\right) V_{t}^{B B} \\
\mathrm{GDP}_{t}=x_{t} y_{t} \mathrm{TP}_{t}^{A}+x_{t}\left(1-y_{t}\right) \mathrm{TP}_{t-1}^{A}+\left(1-x_{t}\right) y_{t} \mathrm{TP}_{t-1}^{B}+\left(1-x_{t}\right)\left(1-y_{t}\right) \mathrm{TP}_{t}^{B}
\end{gathered}
$$


We then express the agents that adopt fully depreciating society as a ratio of the total populations as $\rho_{t}$. This population ratio in this sector: $\rho_{t}$ represents the depreciation or discount rate for payoffs on the level of the previous period in the private business sector. On the other hand, $1-\rho_{t}$ represents the population ratio of the agents in the system control sector that adopt fully evaluating society. Based on the above configuration and the already described Eqs. (16) or (17) in Sect. 4, we can define the replicator dynamics for the system control sector $\left(\mathrm{GDP}^{0}\right.$ for full evaluation-type society and $\mathrm{GDP}^{1}$ for full depreciation-type society).

$$
\rho_{t+1}=\frac{\rho_{t}^{2} \mathrm{GDP}_{t}^{0}+\rho_{t}\left(1-\rho_{t}\right) \mathrm{GDP}_{t-1}^{0}}{\rho_{t}^{2} \mathrm{GDP}_{t}^{0}+\rho_{t}\left(1-\rho_{t}\right) \mathrm{GDP}_{t-1}^{0}+\left(1-\rho_{t}\right) \rho_{t} \mathrm{GDP}_{t-1}^{1}+\left(1-\rho_{t}\right)^{2} \mathrm{GDP}_{t}^{1}}
$$

Then based on Eqs. (19) and (20) in Sect. 4, we can construct the real social system as (41) and (42), which is controlled by policy objective, in proportion to the selection ratios of the two virtual social systems calculated in the system control sector. The inter-system control model presented in this section is a simulation model that manages a sustainable growth path through the depreciation of values which knowledge stocks yield.

$$
\begin{aligned}
& x_{t+1}=\frac{x_{t} y_{t} U_{t}^{A A}+\left(1-\rho_{t}\right) x_{t}\left(1-y_{t}\right) U_{t-1}^{A A}}{x_{t} y_{t} U_{t}^{A A}+\left(1-\rho_{t}\right) x_{t}\left(1-y_{t}\right) U_{t-1}^{A A}+\left(1-\rho_{t}\right)\left(1-x_{t}\right) y_{t} U_{t-1}^{B B}+\left(1-x_{t}\right)\left(1-y_{t}\right) U_{t}^{B B}} \\
& y_{t+1}=\frac{y_{t} x_{t} V_{t}^{A A}+\left(1-\rho_{t}\right) y_{t}\left(1-x_{t}\right) V_{t-1}^{A A}}{y_{t} x_{t} V_{t}^{A A}+\left(1-\rho_{t}\right) y_{t}\left(1-x_{t}\right) V_{t-1}^{A A}+\left(1-\rho_{t}\right)\left(1-y_{t}\right) x_{t} V_{t-1}^{B B}+\left(1-y_{t}\right)\left(1-x_{t}\right) V_{t}^{B B}}
\end{aligned}
$$

Let us present the simulation results using the model of inter-system control. ${ }^{10}$ Table 4 shows numerical calculation results with the initial values of the depreciation rates " $\rho_{t}$ " varying from 0.01 to 0.99 . Phase change trend in the knowledge stock domains causes long-term economic growth with technological change, which is realizing with the high frequency of over 0.9 when starting at $0.01-0.10,0.21-0.40$ and $0.61-0.80$. But it should be noted that the depreciation rates " $\rho_{t}$ " can be induced to change gradually and smoothly when starting at $0.01-0.10$ and $0.21-0.40$ of relatively low values, on the other hand, fiercely and drastically when starting at $0.61-0.80$ of relatively high values. The former cases seem to be more likely in the real society.

\footnotetext{
${ }^{10}$ As in "Appendix 1", we are setting $a=1.8$ and $c=9.5$. The long-term economic growth with technological change can be realized with the range of $a=1.67-2.03$ and $c=9.00-10.16$. According to the results of the numerical calculations of the model in this paper, the maximal Lyapunov exponent is positive stably when $c$ is over 9.1 (positive almost stably when $c$ is over 8.6) [for details, see Sakaki (2004b)].
} 
Table 4 Simulation results for each initial value of $\rho$

\begin{tabular}{|c|c|c|c|c|c|c|c|c|}
\hline \multirow[t]{3}{*}{$\rho$ _InitialValue } & \multicolumn{3}{|c|}{ Knowledge Stock Trend } & \multicolumn{5}{|c|}{$\rho \_$Coefficent Trend } \\
\hline & \multirow[t]{2}{*}{ Lock in } & \multirow[t]{2}{*}{ Phase Change } & \multirow[t]{2}{*}{ Almost Neutral } & \multicolumn{2}{|c|}{ Staying High or Increasing Trend } & \multicolumn{3}{|c|}{ Staying Low or Decreasing Trend } \\
\hline & & & & Lock in to "1" & Fluctuations & Lock in to "0" & Gradual Fluctuations & Fierce Fluctuations \\
\hline $0.01 \sim 0.10$ & 0.00 & 1.00 & 0.00 & 0.00 & 0.00 & 0.00 & 1.00 & 0.00 \\
\hline $0.11 \sim 0.20$ & 0.50 & 0.50 & 0.00 & 0.00 & 0.00 & 0.50 & 0.50 & 0.00 \\
\hline $0.21 \sim 0.30$ & 0.00 & 1.00 & 0.00 & 0.00 & 0.00 & 0.00 & 1.00 & 0.00 \\
\hline $0.31 \sim 0.40$ & 0.00 & 0.90 & 0.10 & 0.00 & 0.00 & 0.00 & 1.00 & 0.00 \\
\hline $0.41 \sim 0.50$ & 0.00 & 0.20 & 0.80 & 0.00 & 0.40 & 0.00 & 0.60 & 0.00 \\
\hline $0.51 \sim 0.60$ & 0.00 & 0.20 & 0.80 & 0.00 & 0.70 & 0.00 & 0.20 & 0.10 \\
\hline $0.61 \sim 0.70$ & 0.10 & 0.90 & 0.00 & 0.00 & 0.00 & 0.10 & 0.10 & 0.80 \\
\hline $0.71 \sim 0.80$ & 0.10 & 0.90 & 0.00 & 0.00 & 0.00 & 0.10 & 0.00 & 0.90 \\
\hline $0.81 \sim 0.90$ & 0.60 & 0.40 & 0.00 & 0.00 & 0.00 & 0.70 & 0.00 & 0.30 \\
\hline $0.91 \sim 0.99$ & 1.00 & 0.00 & 0.00 & 0.00 & 0.00 & 1.00 & 0.00 & 0.00 \\
\hline
\end{tabular}

Each item in the table is expressed by the ratio in each category consisting of the knowledge stock and $\rho$
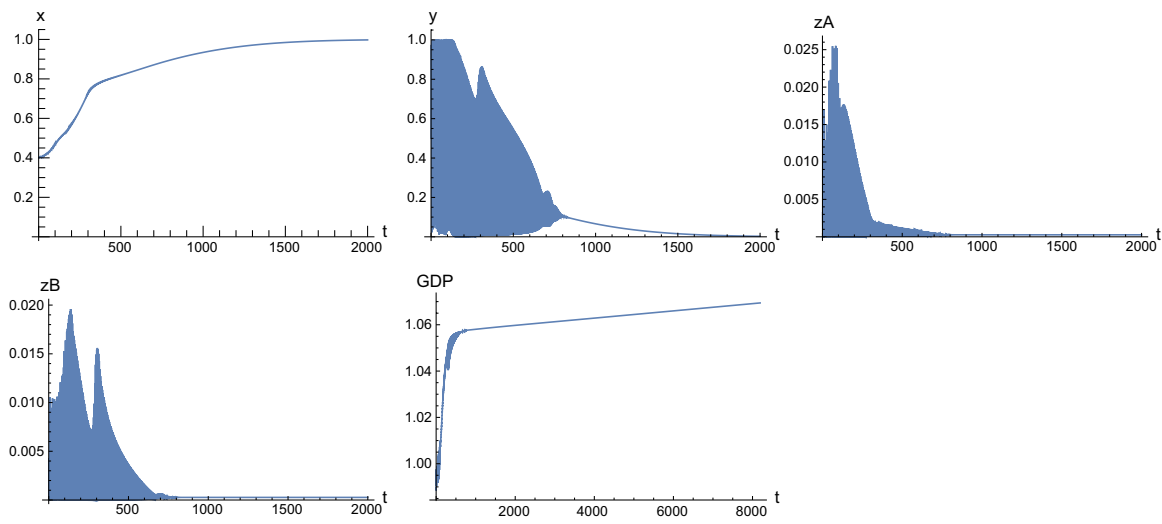

Fig. 4 The case of $\rho_{t}=0$ (full evaluation-type society)
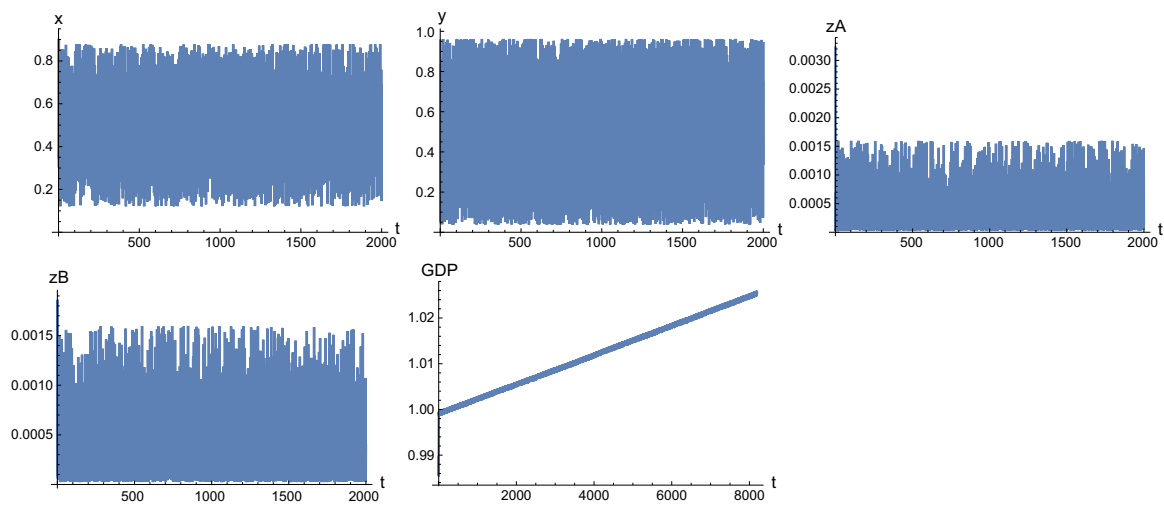

Fig. 5 The case of $\rho_{t}=1$ (full depreciation-type society) 

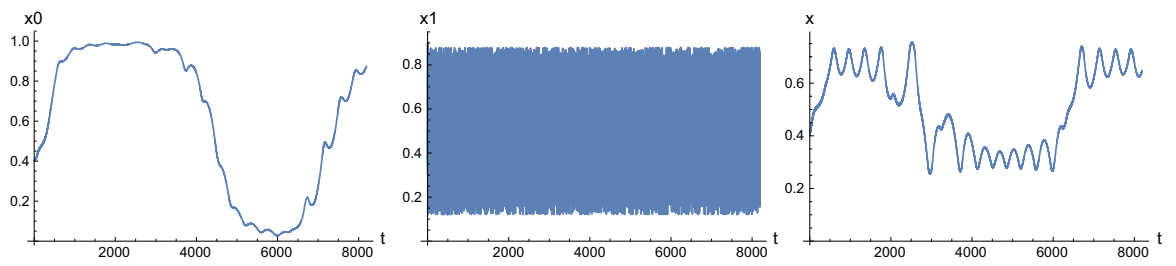

Fig. 6 The case of implementation of inter-system control with $\rho_{t}$ starting at 0.02 . Knowledge stock selection ratio of business companies $X$ in the fully evaluating virtual social system, the fully depreciating virtual social system and the inter-system controlled real social system, respectively, from the left
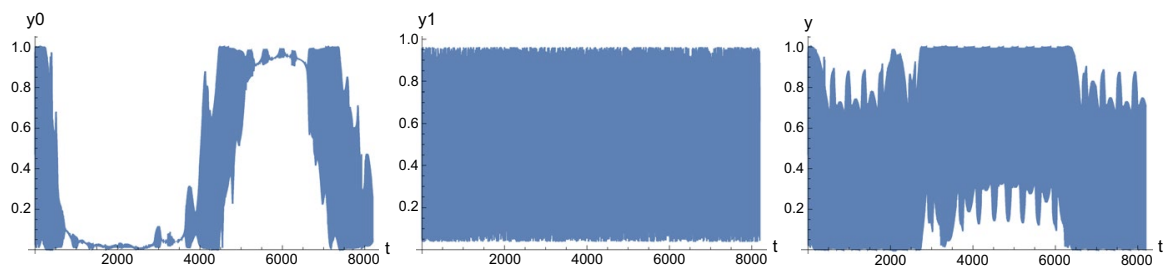

Fig. 7 The case of implementation of inter-system control with $\rho_{t}$ starting at 0.02 . Knowledge stock selection ratio of financial institutions $Y$ in the fully evaluating virtual social system, the fully depreciating virtual social system and the inter-system controlled real social system, respectively, from the left

Next, let us demonstrate the three representative cases as follows. Figure 4 is the full evaluation-type case where the coefficient of control by the system control sector, in other words, the depreciation rate $\rho_{t}$ is fixed at 0 . Figure 5 is the full depreciation-type case where $\rho_{t}$ is fixed at 1 . Figure 6 shows the case of inter-system control using aggregate output values as the evaluation standard.

Of these, in the full evaluation-type case, both groups (business companies $X$ and financial institutions $Y$ ) "lock-in" to one of the knowledge stock domains. Then $\mathrm{R} \& \mathrm{D}$ ratios to knowledge stock $A$ and $B\left(z_{t}^{A}\right.$ and $\left.z_{t}^{B}\right)$, both lower to and remain at 0 . As a result, aggregate output value (illustrated as "GDP" in the figures) also grows rapidly in the process of knowledge stock dissemination, but in the end, growth stops together with the "locking-in" around 1.06 (Fig. 4).

In addition, in the full depreciation-type case, in both groups (business companies $X$ and financial institutions $Y$ ), the changes in knowledge stock domains are drastic and there is no proper dissemination to society. Then R\&D ratios to knowledge stock $A$ and $B$, both stay at low level over time. As a result, aggregate output value remains at a low level around 1.02 over (Fig. 5).

However, in the case implementation of inter-system control through the depreciation rate with aggregate output value as the evaluation standard, in both groups (business companies $X$ and financial institutions $Y$ ), the dissemination and change of knowledge stock domains occur with $\mathrm{R} \& \mathrm{D}$ ratios to knowledge stock $A$ and $B$ maintaining a reasonable level, while at the same time aggregate output value maintains s-shaped growth over time (Figs. 6, 7, 8). In other words, the third case, through control of the depreciation rate, realizes sustainable growth in actual society by 



Fig. 8 The case of implementation of inter-system control with $\rho_{t}$ starting at 0.02 . R\&D ratios to knowledge stock $A$ and $B$, and the aggregate output value (GDP), respectively, from the left
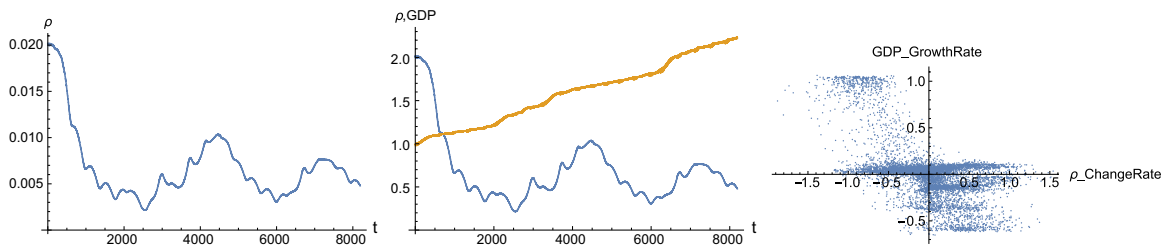

Fig. 9 The transition of the control parameter (depreciation rate) in the case of implementation of intersystem control with $\rho_{t}$ starting at 0.02 . The left figure shows changes in controlled depreciation rate. Middle figure shows changes in aggregate output values (e.g., GDP) and depreciation rate. Right drawing is scatter plot of the rate of change of aggregate output values (GDP) and depreciation rate

combining the characteristics of the first two cases. That is, they are growth potential through the dissemination of knowledge, which is the characteristic of the full evaluation-type society, and the transition to a new growth path through knowledge stock change, which is the characteristic of a full depreciation-type society. As a result, real social system, which is under inter-system control on policy objective, realizes twice as much aggregate output values as both virtual social systems.

More specifically, what kind of inter-system control is required to achieve sustainable growth? If we look at the figure on the right of Fig. 9, generally if the growth rate of aggregate output values is positive, the rate of change in the depreciation rate is negative, and conversely if the growth rate of aggregate output is negative, the rate of change in the depreciation rate tends to be positive. In other words, if the productivity of the relevant knowledge stock is high, the control system lowers the depreciation rate to disseminate the knowledge stock to society and thereby maintain growth, whereas if productivity has declined, the control system raises the depreciation rate to achieve a change to another knowledge stock. As a result of this control, long-term growth through knowledge stock change may be possible.

Moreover, if we closely look at the figure in the middle of Fig. 9, at the beginning of the period of low growth in aggregate output values and regardless of whether aggregate output values are in the middle of a high growth period, the depreciation rate tends to rise ahead of schedule. In other words, to maintain long-term growth, the possibility that an early knowledge stock change is required, even if this means sacrificing the high productivity of existing knowledge stock, can be identified. 


\section{References}

Cantner U, Savin I, Vannuccini S (2016) Replicator dynamics in value chains: explaining some puzzles of market selection. Working paper 83, Karlsruher Institut für Technologie. http://econpapers.wiwi.kit. edu/downloads/KITe_WP_83.pdf. Accessed 5 Aug 2018

Deguchi H (2000) Economics as an agent-based complex system. Union of Japanese Scientists and Engineers Publishing Co., Ltd, Tokyo

Dosi G (1990) Finance, innovation, and industrial change. J Econ Behav Organ 13:299-319

Dosi G, Orsenigo L (1988) Coordination and transformation: an overview of structures, behavior and changes in evolutionary environments. In: Dosi G, Freeman C, Nelson R, Silverberg G, Soete L (eds) Technical change and economic theory. Pinter Publishers, London

Sakaki S (2004a) Management model for technological change and sustainable growth. Evol Inst Econ Rev 1-1:107-125

Sakaki S (2004b) Research on the possibility of sustainable economic growth through knowledge stock management: elucidation of technological change mechanism through simulation model and empirical research in Japanese economy. Ph.D. Thesis, Graduate School of Humanities and Sociology, The University of Tokyo

Sakaki S (2009) Where do we stand on the intellectual property rights system between "open access and reinforcing private ownership"? Evol Inst Econ Rev 5-2:225-258

Sakaki S (2015) ICT business. Corona Publishing Co., Ltd, Tokyo

Sakaki S (2017) Income distribution management for sustaining long-term economic growth: does the equalization of income distribution contribute to long-term economic growth? Evol Inst Econ Rev Evol Inst Econ Rev 14-2:363-395

Sakaki S (2018) A simple method of evolutionary growth modeling. Working Paper

Scherer FM (1999) New perspectives on economic growth and technological innovation. Brookings Institution Press, Washington, DC

Weibull JW (1995) Evolutionary game theory. MIT Press, Cambridge

Yoshikawa H (2000) Modern macroeconomics. Sobunsha Publishing Co., Ltd, Tokyo 